\title{
Cardiac MRI functional assessment of bioprosthetic mitral valves: an in vitro comparison against doppler echocardiography
}

Dimitrios Maragiannis ${ }^{*}$ Matthew Jackson, Karen Chin, Stephen Igo, Kyle Autry, William A Zoghbi, Dipan J Shah, Stephen H Little

From 18th Annual SCMR Scientific Sessions

Nice, France. 4-7 February 2015

\section{Background}

Evaluation of bioprosthetic mitral valve (BMV) function remains an important goal in clinical practice. We hypothesized that cardiac MRI (CMR) is accurate in measuring transvalvular flow volume and anatomic orifice area (AOA) in normal and obstructed BMVs in an in vitro model.

\section{Methods}

Four sizes of normal BMVs $(27,29,31,33 \mathrm{~mm})$ and 4 stenotic BMVs $(27 \mathrm{~mm}$ and $29 \mathrm{~mm}$; with one or two leaflet

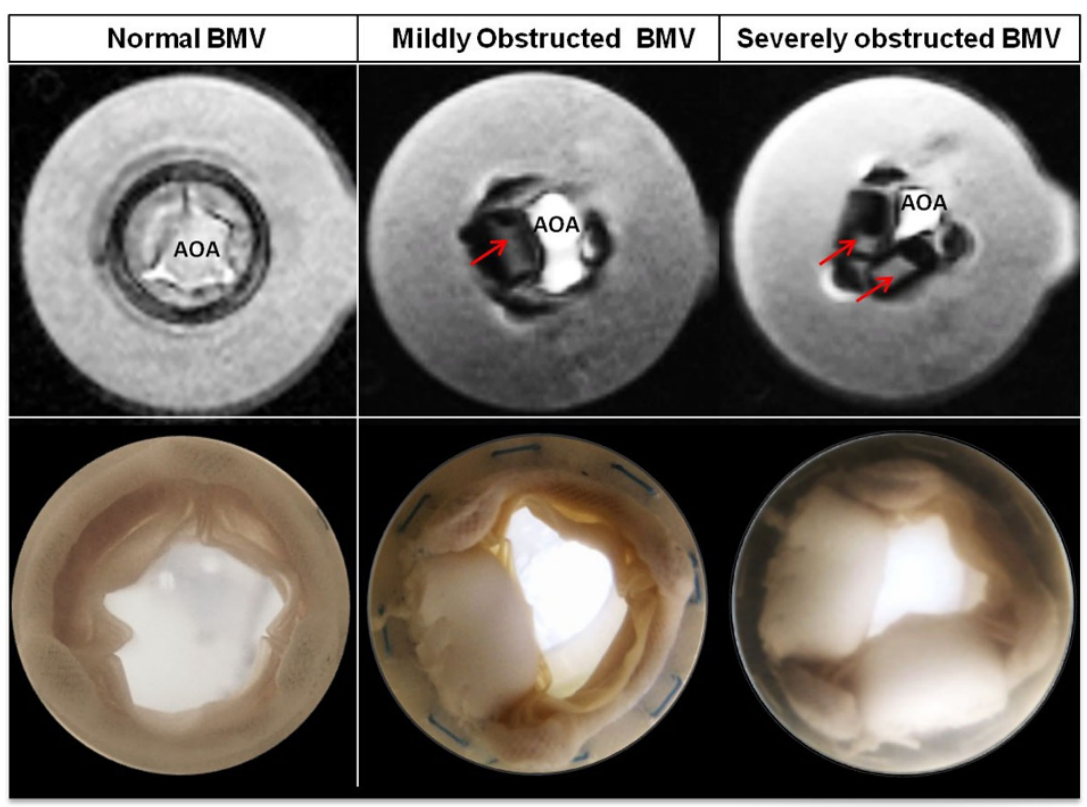

Figure 1 
obstructions representing mild and severe stenosis) were evaluated in a pulsatile in vitro heart chamber under 3 flow conditions $(70 \mathrm{ml}, 90 \mathrm{ml}, 110 \mathrm{ml} /$ beat $)$ at rate of 70 beats/ $\mathrm{min}$. All constructs were evaluated by phase-contrast (PC) CMR; the reference standards for comparison were continuous wave Doppler imaging, and standard flowmetry.

\section{Results}

CMR methods accurately measured transvalvular flow and correlated strongly with flow transducer measurements $(\mathrm{N}=24 ; \mathrm{r}=0.961, \mathrm{p}<0.001)$. Bland-Altman analysis demonstrated a $95 \%$ confidence interval from -9.5 to $8.6 \mathrm{ml} /$ beat across the range of both normal (mean EOA $=1.82 \mathrm{~cm}^{2}$ ) and obstructed valves (mean $\mathrm{EOA}=0.96 \mathrm{~cm}^{2}$ ). Anatomic orifice area (AOA) correlated well with Doppler effective orifice area (EOA) $(r=0.986, p<0.001)$; AOA was larger than EOA as expected (mean difference was $0.68 \mathrm{~cm}^{2}$ ). Furthermore, peak velocity by phase contrast CMR correlated strongly with Doppler peak velocity $(r=0.984$, $\mathrm{p}<0.001)$. Bland-Altman analysis revealed a $95 \%$ confidence interval of -44.4 to $19.36 \mathrm{~cm} / \mathrm{sec}$.

\section{Conclusions}

PC-CMR methods accurately assess bioprosthetic transvalvular flow, peak velocity and orifice area. The CMR methods described hold promise in evaluating bioprosthetic mitral valve function in cardiac MRI studies, particularly when Doppler methods are unobtainable or discordant.

\section{Funding}

American Heart Association grant \#11BGIA5840008.
doi:10.1186/1532-429X-17-S1-P335

Cite this article as: Maragiannis et al:: Cardiac MRI functional assessment of bioprosthetic mitral valves: an in vitro comparison against doppler echocardiography. Journal of Cardiovascular Magnetic Resonance 201517 (Suppl 1):P335.
Submit your next manuscript to BioMed Central and take full advantage of:

- Convenient online submission

- Thorough peer review

- No space constraints or color figure charges

- Immediate publication on acceptance

- Inclusion in PubMed, CAS, Scopus and Google Scholar

- Research which is freely available for redistribution

Submit your manuscript at www.biomedcentral.com/submit 